\title{
COMPUTATIONAL AND RAPID EXPECTED ANNUAL LOSS ESTIMATION METHODOLOGIES FOR STRUCTURES
}

\author{
Kevin M Solberg ${ }^{1}$, Rajesh P Dhakal ${ }^{*}$, John B Mander ${ }^{1}$, and Brendon A Bradley ${ }^{1}$ \\ ${ }^{1}$ Department of Civil Engineering, University of Canterbury, Private Bag 4800, Christchurch 8020, New Zealand \\ ${ }^{*}$ Corresponding author: $\mathrm{Ph}+64-3-3642987$ ext 7673; Fax: +64-3-3642758; \\ Email: rajesh.dhakal@canterbury.ac.nz
}

\section{SUMMARY}

Expected annual loss (EAL), which can be expressed in dollars, is an effective way of communicating the seismic vulnerability of constructed facilities to owners and insurers. A simplified method for estimating EAL without conducting time consuming non-linear dynamic analyses is presented. Relationships between intensity measures and engineering demand parameters resulting from a pushover analysis and a modified capacity-spectrum method are combined with epistemic and aleatory uncertainties to arrive at a probabilistic demand model. Damage measures are established to determine thresholds for damage states from which loss ratios can be defined. Financial implications due to damage can then be quantified in the form of EAL by integrating total losses for all likely earthquake scenarios. This rapid loss estimation method is verified through the computationally intensive Incremental Dynamic Analysis, with results processed using a distribution-free methodology. To illustrate the application of the proposed method, the seismic vulnerability of two highway bridge piers is compared; one bridge is traditionally designed for ductility while the other is based on an emerging damage avoidance design (DAD) philosophy. The DAD pier is found to have a clear advantage over the conventional pier; the EAL of the DAD pier is less than 20 percent of its ductile counterpart. This is shown to be primarily due to its inherent damage-free behaviour for small to medium earthquake intensities, whose contribution to EAL is significantly more than that of very rare events. 


\section{KEYWORDS}

Expected Annual Loss (EAL); Performance Based Earthquake Engineering (PBEE); Incremental Dynamic Analysis (IDA); seismic financial risk; Damage Avoidance Design (DAD)

\section{INTRODUCTION}

One primary aim of Performance-Based Earthquake Engineering (PBEE) is to predict, with a certain level of confidence, the seismic performance of structures at various levels of earthquake excitation (seismic demand). This requires the engineer to understand seismic risk and its inherent uncertainty. As an adjunct to conventional design it is desirable that the engineer be able to communicate that risk in a way easily understood by stake-holders such as owners, bankers, and insurers. One primary development in PBEE is the Pacific Earthquake Engineering Research (PEER) Centre's probability framework equation which can be used to arrive at a mean annual frequency of a decision variable. An early application and theory outlining the PEER framework equation is given in [1]. For example, this equation can be used to determine the closure probability of a building at a specific site. This is done by: quantifying the rate of exceedance of a level of ground shaking; interrelating the level of ground shaking with structural response and the structural response with damage; and quantifying the likelihood of facility closure given a certain level of damage. Thus, it is apparent that the triple integral equation can be broken into four subtasks: (i) assessment of seismic hazard; (ii) analysis for structural response; (iii) quantification of damage; and (iv) estimation of damage consequence in terms of a chosen decision variable. Implicit in the formula is a probabilistic analysis, incorporating both randomness and uncertainty and combining this variability in accordance with the total probability theorem. The manner in which this formula is applied, its limitations, and its potential expansion, have been the subject of rigorous research, both within and outside PEER. A good overview of such developments is given in [2].

One expansion of the framework formula would be the integration of scenario losses over the entire range of occurrence probability, resulting in quantification of seismic risk in terms of an Expected Annual Loss (EAL) [3]. The advantage of EAL is that it incorporates a range of seismic 
scenarios, return rate, and expected damage into a single mean dollar loss. By using an interest rate, the time value of EAL for each year in the remaining life period of a structure can be transformed to a net present value of the total losses in the lifetime of the structure. When this net present value of the potential loss is added to the initial cost of the construction/retrofit, the resulting sum can be a very sound and convincing parameter, based on which rational decisions can be made to select the most effective among the available design and/or retrofitting alternatives.

Although several methods of financial risk assessment have been presented, no method has yet been widely adopted. One detailed method introduced by Porter et al. [4] is Assembly Based Vulnerability (ABV). It is especially good at estimating the overall damage to a building based on the damage to its individual components. The aleatory uncertainty was expressed by fragility curves, representing the possible distribution of a variable which normally conforms to a lognormal distribution $[5,6]$. If aleatory and epistemic uncertainties are considered in each of the subtasks in the risk assessment process, the simulation-based calculation can become very time onerous [7]. Attempts have been made to simplify the computation process. Cornell et al. [8] used data generated from a series of non-linear time-history analysis and proposed a power-law equation for the median curve. If the hazard-recurrence relationship is also expressed in a similar algebraic form, it is possible to combine the two equations and come up with a closed form solution that can be used to determine the rate of exceeding a demand parameter (i.e. interstory drift) given a period of time.

A primary step within PBEE is defining a relationship between specified demand levels and a hazard environment. This relationship, termed the demand model, has gained a lot of attention in the past decade. Vamvatsikos and Cornell [9] have researched the feasibility of Incremental Dynamic Analysis (IDA) as a means of relating these parameters. An IDA basically consists of performing a series of time-history analyses to arrive at a set of demand parameters, obtained by scaling a suite of earthquake records to various intensities. It is similar (though far superior) to a static pushover in that it encompasses the entire range of likely behaviour, from pre-yield to collapse. This method has gained considerable acceptance since its inclusion in emerging 
regulations [10]. Other simplified methods have been proposed by Porter and Beck [11], who by assuming that seismic risk is dominated by non-structural damage from moderate events, proposed a simple linear elastic analysis to replace the often cumbersome non-linear dynamic analysis. The non-linear dynamic procedure is considerably more time consuming and requires uncommon skills for practicing engineers, whereas the linear approach is relatively simple. Nevertheless, the assumptions made in the linear method may not be valid for all structures, specifically those designed to behave well in the non-linear range.

A generic procedure is needed that will consider non-linear behaviour and a range of uncertainty, while retaining a degree of simplicity. Vamvatsikos and Cornell [12] have established that it is possible to relate a static pushover curve to IDA. This paper will set out to estimate EAL using a rapid analysis approach, referred to hereafter as the Rapid IDA-EAL approach. The Rapid IDA-EAL method will be verified by a rigorous computational IDA. For this verification analysis, in order not to bias the latter through a priori assumptions in the choice of probability density functions, a distribution-free analysis method is introduced. Hereafter, this is referred to as the Computational IDA-EAL distribution-free approach. A case study of two different bridge piers will illustrate the effectiveness of the approaches for estimating EAL.

\section{EAL FRAMEWORK}

In order to conduct a financial risk analysis, it is necessary to form relationships between the multiple facets of the assessment process. This can be accomplished by implementing the PEER triple integral equation [1]:

$$
v(d v)=\iiint G(d v \mid d m)\left|d G(d m \mid e d p)\|d G(e d p \mid i m)\| d f_{a}(i m)\right|
$$

in which $f_{a}(\bullet)=$ the annual rate of exceedance of $(\bullet)$; im $=$ intensity measure (e.g. peak ground acceleration, spectral acceleration); $e d p=$ engineering demand parameter (e.g. maximum drift angle); $d m=$ damage measure (e.g. repairable/irreparable damage, collapse); $d v=$ decision variable (e.g. loss ratio, downtime); and $G(x \mid y)=P(x>X \mid y=Y)$; the conditional complimentary cumulative 
distribution function (CCDF). Absolute value signs are required for each of the terms in Equation (1), as some of the derivatives of the CCDF's may be negative.

Equation (1) gives the mean annual rate of exceedance of a decision variable $d v$. In order to compute EAL all losses must be integrated over the entire range of probability [3]:

$$
E A L=\int_{0}^{\infty} L_{r}\left|d P\left(L_{r}\right)\right|
$$

where $L_{r}=$ loss ratio (the $d v$ in this case) defined as the cost to repair a structure divided by the total replacement cost; and $P\left(L_{r}\right)=$ probability of loss ratio exceeding a specified value $L_{r}$.

It is to be noted that rate and probability are numerically similar for small values $(v<0.01)$ but deviate for larger values $[13,14]$. Rate can be converted to probability using a temporal relationship. In this work, for simplicity the Poisson model will be used. Hence, the relationships between rate and probability and between their derivatives are given by:

$$
\begin{gathered}
P=1-e^{-f_{a}} \\
d P(i m)=e^{-f_{a}} d f_{a}(i m)
\end{gathered}
$$

where $P=$ Probability of exceedance; and $f_{a}=$ rate of exceedance. If $d f_{a}(\mathrm{im})$ is replaced with $d P(\mathrm{im})$ in Equation (1) and the decision variable is replaced with loss ratio, then the result is the probability of exceeding a loss ratio, $P\left(L_{r}\right)$. Hence, EAL can be calculated by substituting Equation (1) (using $d P\left(\right.$ im) ans $\left.P\left(L_{r}\right)\right)$ into Equation (2) to obtain:

$$
E A L=\iiint \int L_{r} d G\left(L_{r} \mid d m\right)\left|d G(d m \mid e d p)\|d G(e d p \mid i m)\| e^{-f_{a}} d f_{a}(i m)\right|
$$

Equation (5) provides the basis of the EAL calculations presented in this paper.

\section{RAPID IDA-EAL METHODOLOGY}

The concept of the proposed Rapid IDA-EAL procedure is relatively straightforward. It is possible to generate the median Intensity Measure (IM) versus Engineering Demand Parameter (EDP) relationship from a non-linear static pushover analysis and a modified Capacity Spectrum Method (CSM). The use of the CSM to characterise the IM-EDP relationship, as opposed to IDA [9], allows a significant reduction in time demands of the financial assessment. This occurs as a result of the CSM being able to be computed by hand calculator (or simple spreadsheet) within 
minutes, while conducting IDA for a suite of ground motion records at various intensities, can take up to a day or longer (depending on the number of degrees of freedom in the structural model).

This Rapid IDA-EAL methodology utilizes the customary assumption that variability conforms to a lognormal distribution $[5,6,15,16]$, allowing fragility curves to be generated for discrete states of damage. The fragility curves are then transformed via the seismic hazard model into hazardsurvival curves for each damage state. Then, financial implications of the different damage states are considered together with the corresponding hazard-survival curves to arrive at the EAL. This general process is outlined in detail through the following steps.

\section{Step 1: Conduct Pushover Analysis}

A non-linear static pushover analysis is performed to assess the capacity of the system, as illustrated in Figure 1a. From the pushover curve, it is possible to calculate the secant (equivalent elastic) period $T$ in terms of normalized base shear capacity $C_{c}$ and peak response displacement $\Delta$ as follows:

$$
T=2 \pi \sqrt{\frac{M}{K}}=2 \pi \sqrt{\frac{W}{g} \frac{\Delta}{C_{c} W}}=2 \pi \sqrt{\frac{\Delta}{C_{c} g}}
$$

in which $C_{c}$ can be expanded as $C_{c}=F_{y} / W$ where $F_{y}=$ base shear force; $W=$ seismic weight; $M=$ seismic mass; $K=$ secant stiffness; and $g=$ acceleration of gravity.

\section{Step 2: Establish Median Spectrum-Compatible IDA Curve}

The evaluation of seismic demand at various effective damping levels depends on the portion of the spectrum governing response. Figure $1 \mathrm{~b}$ illustrates the seismic demand spectrum and the regions of constant spectral acceleration, spectral velocity, and spectral displacement as limited by $T_{a}, T_{v}$, and $T_{d}$. For the constant acceleration, velocity and displacement regions, the demand spectrum is given by Equations (7)-(9), respectively:

$$
\begin{gathered}
C_{d}=\frac{F_{a} S_{s}}{B_{a}} \\
C_{d}=\frac{F_{v} S_{1}}{T B_{v}}
\end{gathered}
$$




$$
C_{d}=\frac{F_{v} S_{1} T_{d}}{T^{2} B_{d}}
$$

where $F_{a}$ and $F_{v}$ are factors to adjust spectral acceleration for short and long period structures at different soil classes; $S_{s}$ and $S_{1}$ are spectral acceleration at short periods and the one second period; and $B_{a}, B_{v}$, and $B_{d}$ are factors based on effective viscous damping for the constant spectral acceleration, velocity, and displacement regions, respectively. Because of the formulation of the equations, for a given effective (secant) period of vibration $T$, the equation applicable in that range always yields a lower $C_{d}$ than the other two equations. Hence, the normalized base shear demand can also be calculated as the lesser of Equations (7)-(9).

Employing the CSM, it is possible to relate the capacity-displacement curve (i.e. pushover curve) and the Acceleration-Displacement Response Spectrum (ADRS) curve by combining them into a single plot as illustrated in Figure 1c. The "performance point" of the structure is estimated from the intersection of the pushover curve with the damping-reduced ADRS curve. The CSM, as presented in ATC-40 [17], has come under considerable scrutiny due to inconsistent displacement predictions $[18,19]$. Such errors have proved to be rectified by use of either the inelastic spectra or a modified CSM as described by Iwan [20].

To further address these issues, this study has adopted modified damping approximations proposed by Lin and Chang [21] coupled with the reduction in equivalent viscous damping due to the pinched nature of the real hysteresis curves, as introduced by Pekcan et al. [22]. Based on recent studies by Lin and Chang [21], confirmed by Lin et al. [23], and modified herein as part of the present study, the damping-related reduction factors, $B_{a}, B_{v}$, and $B_{d}$ can be calculated as a function of effective damping, $\xi_{\text {eff }}$ as follows:

$$
\begin{aligned}
& B_{a}=\sqrt{\frac{2+\xi_{\text {eff }}}{7}} \\
& B_{d}=\sqrt{\frac{8+\xi_{\text {eff }}}{13}}
\end{aligned}
$$

The damping factor for the constant spectral velocity range, $B_{v}$ can be calculated by linear interpolation between $B_{a}$ and $B_{d}$ based on period or spectral displacement. Total effective viscous

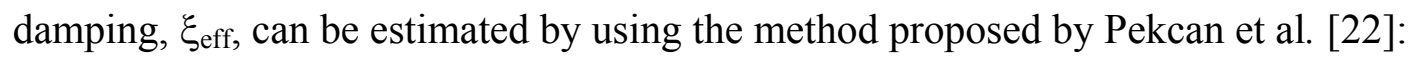




$$
\xi_{e f f}=\xi_{o}+\xi_{h y}=\xi_{o}+\frac{2}{\pi} \eta \frac{\left(1-\alpha_{s}\right)(1-1 / \mu)}{\left(1-\alpha_{s}+\mu \cdot \alpha_{s}\right)}
$$

where $\xi_{\mathrm{o}}=$ intrinsic damping of an elastic system; $\eta=$ the efficiency factor defined as the ratio of the actual area within a hysteresis loop to that of the idealized bi-linear loop (Figure 1c); $\alpha_{s}=$ postyield stiffness to initial stiffness ratio; $\mu=\Delta_{\max } / \Delta_{\text {yield }}$ where $\Delta=$ displacement at the seismic centre of mass of the structure.

Setting $C_{c}=C_{d}$ and substituting Equation (6) into (7), (8), and (9), the one second spectral acceleration $\left(F_{v} S_{l}\right)$ for a given demand can be found. Thus for the median-spectrum compatible IDA curve shown in Figure 1d, the IM (spectral acceleration) can be found for a given EDP (displacement) by the greater (i.e. the inverse of the lesser) of the following three equations:

$$
\begin{gathered}
F_{v} S_{1}=T_{v} \cdot B_{a} \cdot C_{c} \\
F_{v} S_{1}=2 \pi \sqrt{\frac{C_{c} \cdot \Delta}{g}} \cdot B_{v} \\
F_{v} S_{1}=\frac{4 \pi^{2}}{g \cdot T_{d}} \cdot \Delta \cdot B_{d}
\end{gathered}
$$

where generally, $T_{v}$, and $T_{d}$ can be taken as 0.4 and 3.0 seconds, respectively.

The median-spectrum compatible IDA relationship developed using the CSM above is then used as an approximation to the true median IDA relationship. Note that some bias is introduced here, as no ground motion records will ever be able to match the spectrum over the full range of periods. This procedure is used however because of its simple implementation in practice.

\section{Step 3: Define Damage States and Limits}

This study adopts the five damage states (DS1 to DS5) defined by Mander and Basoz [15] that have been used in HAZUS, as summarised in Table 1. The damage state limits are also illustrated in Figure 1d.

\section{Step 4: Incorporate Sources of Variation using Assumed Distributions}

Throughout this process approximations are made regarding damping, material strengths, modelling simplifications, etc. These approximations can be grouped into epistemic uncertainty, where further investigation may lead to an increase in accuracy, and aleotory uncertainty, which 
cannot be reduced because of its random nature. An example of the former would be uncertainty in analytical modelling, and the latter would be the inherent record-to-record randomness of earthquake ground motions. As discussed earlier, previous studies $[5,6,16]$ have shown that aleatory uncertainty approximately conforms to a lognormal distribution. For convenience, it is assumed here that epistemic uncertainties are also lognormally distributed. This two-parameter distribution can be defined with a median $(\tilde{x})$ and a standard deviation of the logarithms of the data, $\beta$, referred to herein as the dispersion factor. Since a formula relating EDP and IM is available, the median values have been established and only the dispersion is left to be determined. It is possible to assume a dispersion based on established trends regarding the various uncertainties discussed. To determine the dispersion of all combined uncertainty and randomness, they are combined by root-sum-squares method [24] used in FEMA $350[8,10]$ :

$$
\beta_{C / D}=\sqrt{\beta_{D}{ }^{2}+\beta_{C}{ }^{2}+\beta_{U}{ }^{2}}
$$

where $\beta_{D}=$ aleatory variation of structural response due to the input motion; $\beta_{C}=$ aleotory uncertainty in structural capacity (e.g. uncertainty in the DS given a certain level of EDP); and $\beta_{U}=$ epistemic modelling uncertainty (e.g. damping, hysteresis models, fixity conditions, soil-structure interaction and material properties). In this study, recommendations of FEMA 350 [10] have been adopted; i.e. $\beta_{C}=0.2$ and $\beta_{U}=0.25$. Although $\beta_{D}$ is difficult to quantify, it varies depending on the parameter used as the IM and the value of IM itself [16]. Using spectral acceleration at the natural period of the structure as the IM (i.e. $I M=S_{a}\left(T_{1}\right)$ ) investigations into the variation of input motion were conducted by the authors. It was noted that the variation of $\beta_{D}$ for different levels of a given IM can be approximated by the relationship:

$$
\beta_{D}=\beta_{D B E} \sqrt{\frac{I M}{I M_{D B E}}}
$$

where $\beta_{D B E}=$ dispersion of the structural response due to ground motions with IM scaled to the design basis earthquake level, $I M_{D B E}$. With the calculated median IM's $\left(\mathrm{S}_{\mathrm{a}}\left(\mathrm{T}_{1}\right)\right.$ in this case) and the resulting $\beta_{C / D}$, fragility curves are plotted as in Figure 1e. Fragility curves are drawn giving the probability of exceeding a damage state for a given value of $\mathrm{S}_{\mathrm{a}}\left(\mathrm{T}_{1}\right)$. Unlike other vulnerability 
methods, all uncertainty and randomness are grouped into a single composite dispersion factor, $\beta_{C / D}$, as also adopted in $[8,10]$. This greatly simplifies the subsequent integration.

\section{Step 5: Define a Seismic Hazard-Recurrence Relationship}

To arrive at an EAL, it is necessary to define a relationship between an IM and annual frequency $\left(f_{a}\right)$, which is commonly known as the seismic hazard-recurrence relationship. It is possible to approximate the hazard-recurrence curve by fitting a straight line through two known points in a $\log -\log$ scale:

$$
f_{a}(I M)=k_{o}(I M)^{-k}
$$

where $k_{o}$ and $k$ are empirical constants, that may be obtained through linear regression [8]. Using the 1 second spectral acceleration $\left(F_{v} S_{1}\right)$ as the IM, Figure 1f plots Equation (18) which can also be written as follows for a high seismic zone in New Zealand $(k=3)$ :

$$
f_{a}=\frac{1}{475}\left(\frac{F_{v} S_{1}}{0.4}\right)^{-3}
$$

This simple parametric form of the hazard is inaccurate when extrapolated to more frequent earthquakes; e.g. when $f_{a}>0.01(\mathrm{~T}<100$ years). In such cases, Equation (19) overestimates the hazard. This deficiency can be rectified by disregarding any damage below a certain threshold. In this paper, this threshold is assumed to correspond to $90 \%$ probability of not sustaining any damage. In other words, this is the intersection of the $90^{\text {th }}$ percentile curve and the line serving as the boundary between DS1 (no damage) and DS2 (slight damage).

\section{Step 6: Calculate EAL}

In order to evaluate the EAL, financial implications of the different damage states must be quantified. This is done through a loss ratio (LR), which is the ratio of the repair cost to the total replacement cost. Analytical and/or empirical methods may be used to estimate the loss ratio for a given limit state. Alternately, professional cost estimators can be consulted for reliable estimates. The accuracy of the LR values will naturally depend on the level of detail used in the method/estimate; e.g. if the vulnerability of components are assessed individually and then compiled, it will be significantly more accurate than a single global estimate. In this study, the 
values of LR for different damage states are assumed to be constant. Apart from "no damage" (LR for DS1 = 0) and "collapse" (LR for DS5 = 1), there is however uncertainty associated with the loss ratios for other damage states. This uncertainty can be further introduced into the composite dispersion $\beta_{C / D}$, although it is not done so here.

Hazard-survival curves shown in Figure $1 \mathrm{~g}$ relate the probability of not exceeding a damage state given an annual frequency, and these curves must be integrated and multiplied with the corresponding LR's to estimate EAL. In other words, EAL is the total volume subtended by the hazard-survival curves for different damage states plotted in the horizontal plane and their corresponding loss ratios plotted in the vertical axis as shown in Figure 1g. Using Gaussian quadrature principles, a direct expression for the numerical integration of a cumulative probability curve conforming to a lognormal distribution covering the total probability range (i.e. between 0 and 1) is:

$$
E A L=\tilde{x}\left[0.75+0.125\left(7^{k \beta}+7^{-k \beta}\right)\right]
$$

where $\beta=$ lognormal standard deviation from Equation (16) and $k=$ hazard recurrence parameter defined above. In Equation (20), the median variable $\tilde{x}$ for $n$ damage states is defined as:

$$
\widetilde{x}=\sum_{i=1}^{n} f_{a_{i}} \Delta L R_{i}
$$

where $\Delta L R_{i}=L R_{i}-L R_{i-1}$ and $f_{a_{i}}$ is the annual frequency corresponding to $50 \%$ survival probability of the $i^{\text {th }}$ damage state boundary. Equation (20) was compared with numerical integration, which showed good agreement with results falling within $1 \%$ for $k \beta<2$. This formula, however, is conservative and will lead to a higher EAL since it does not consider the cut-off of damage from frequent events. To account for this, Equation (20) can be modified to truncate the data above the 90\% no-damage confidence threshold:

$$
E A L=\tilde{x}\left[0.6+0.2\left(3.5^{k \beta}+3.5^{-k \beta}\right)\right]
$$

Figure $1 \mathrm{~h}$ illustrates the resulting total loss ratio curve as a function of annual probability. Taking a single value from this curve gives a scenario loss, similar to what the PEER triple integral equation (i.e. Equation (1)) does; the only difference is that the PEER equation uses rate $v$ whereas 
the outcome shown in Figure $1 \mathrm{~h}$ has been obtained by using probability $P$. Performing the additional integration yields the EAL, illustrated as the area under the curve.

To calculate EAL based on the proposed Rapid IDA-EAL, the engineer needs to define only two sets of parameters: the EDP limits for each damage state, and the associated LR's. Once the EAL contributions for each damage state have been calculated using Equations (20) and (22), their summation will give the total EAL for the assumed dispersion. Note that all calculations are based on median values and can be computed by hand. The randomness and uncertainty are combined in a single parameter $\beta$ which is introduced in the process only in the final step. This eliminates difficult integration steps and simplifies the process to such extent that it can be completed in a table.

\section{VERIFICATION OF RAPID-EAL METHOD}

To verify the accuracy of the Rapid IDA-EAL method, a rigorous computational IDA-EAL procedure was developed that does not presume any distributions. Instead, the IDA data is sorted into fractile bands to define the IM-EDP relationship. The hazard-survival curves generated from these computational IDA-EAL curves are then numerically integrated to arrive at EAL. A detailed explanation of this computational approach follows.

\section{Incremental Dynamic Analysis}

The basic concept of IDA has been well researched [9] and is not a focus of this study, but rather the data processing that follows is. A brief description of the analysis technique is presented here for completeness. Conducting an IDA consists of running a series of inelastic dynamic timehistory analyses at various levels of excitation, over a suite of earthquake records. This results in a matrix of data from which a probabilistic IM-EDP relationship is derived. Choosing an appropriate IM is an important step, since it can have significant effect on the scatter of data. Current best practice for the first mode dominated structures is to use the $5 \%$ damped spectral acceleration at the fundamental period of the structure, which has been shown to be relatively 'efficient' and 'sufficient' compared to peak ground acceleration [16]. Due to the lack of large earthquakes in 
New Zealand over the past 100 years, despite its known large seismicity, there are insufficient regional ground motion records to use for the IDA. Therefore a suite of ground motion records, previously used by Vamvatsikos and Cornell [25] were adopted, and are presented in Table 2. These records, which were all recorded on firm soil, have magnitude and distance ranges of 6.5-6.9 and $15.1-31.7 \mathrm{~km}$, respectively.

\section{Sorting and Further Uncertainty Incorporation}

From the resulting IDA data for a given IM $\left(\mathrm{S}_{\mathrm{a}}\left(\mathrm{T}_{1}\right)\right.$ in this case), all of the EDP points are sorted and used to create an empirical CDF [26]. The variability of results from an IDA (using a deterministic structural model) comes solely from the randomness in the input motion. However, other sources of uncertainty and randomness previously discussed must be considered. Knowing that the data will at least loosely conform to a lognormal distribution, it is possible to incorporate this additional uncertainty by modifying the data to incorporate a larger dispersion. It is noted that for consistency, the median of the empirical CDF before and after incorporation of further uncertainties should remain unchanged. Therefore the probability of exceeding a given value, $x$, can be expressed as:

$$
P=\Phi\left(\frac{\ln \left(x_{s}\right)-\ln (\tilde{x})}{\beta_{C / D}}\right)=\Phi\left(\frac{\ln \left(x_{u}\right)-\ln (\tilde{x})}{\beta_{D}}\right)
$$

where $x_{u}=$ unscaled value of $x$ with group dispersion of $\beta_{D}$ that arises from demand randomness only; $x_{s}=$ rescaled value of $x$ that accounts for all sources of aleotory and epistemic uncertainty, $\beta_{C / D}$; and $\Phi(\bullet)$ is the standard normal CDF. Hence it can be seen that the terms inside the brackets must be equal, and hence re-arranging Equation (23) gives:

$$
x_{s}=\tilde{x} \cdot\left|\frac{x_{u}}{\tilde{x}}\right|^{\frac{\beta_{C / D}}{\beta_{D}}}
$$

Note that $\beta_{D}$ is calculated (neglecting data where structural collapse occurred) at each IM and linearly interpolated wherever needed, unlike in the Rapid IDA-EAL method where it is approximated by an empirical relation. The neglect of structural collapse cases is deemed acceptable considering their relatively small contribution (for the modern code-designed structures in this case study) toward EAL [27]. The inclusion of further variability illustrated above can cause 
bias in the scaled values (i.e. the median of the scaled data may not be numerically exactly equal to that of the unscaled data). This bias reduces as the number of data points increases, and for the twenty data points for each IM used in this study, the bias was found to be negligible.

\section{Calculate EAL}

For consistency, all financial loss parameters (DM, LR, and hazard-recurrence) were kept the same as with the Rapid IDA-EAL method establisher earlier. Since particular interest in the Rapid IDA-EAL approximations is the demand model, this will be a focus of the verification process. For a given DM, the corresponding value of IM at each probability interval can be found by linear interpolation of the data. Given the hazard-recurrence relationship, this can be expressed by a hazard-survival curve.

EAL can be found by numerically integrating the given set of data points as:

$$
E A L=\sum_{i=1}^{n} \sum_{j=1}^{m} f_{a_{i}} L R_{j} \frac{1}{n}
$$

where $n=$ total number of earthquake records; $m=$ number of damage states; and $j$ corresponds to each probability interval, which is calculated assuming that the total probability is uniformly distributed between the twenty data points; i.e. the lowest and the highest data correspond to $97.5 \%$ and $2.5 \%$ probability of exceedance with 5\% (100\% divided by 20 data points) difference between successive data points. The formula in Equation (25) yields the area beneath the total loss curve presented in Figure 1h.

\section{CASE STUDY: RC BRIDGE PIERS}

To illustrate the effectiveness of the two methods presented, a case study will be conducted to compare the performance of two highway bridges with substantially different design attributes; the first being a conventional pier designed for ductility (hereafter referred to as the ductile pier), the second a rocking pier designed according to the emerging Damage Avoidance Design (DAD) philosophy (hereafter referred to as the DAD pier). 


\section{Prototype Details}

Consider the reinforced concrete bridge pier shown in Figure 2. The pier is typical of modern design, with 40m spans, $10 \mathrm{~m}$ transverse width, and $7 \mathrm{~m}$ height. The seismic weight of the superstructure is assumed to be $7,000 \mathrm{kN}$ and it is located in a high seismic zone, on a firm soil site in New Zealand. Consequently, the Peak Ground Acceleration (PGA) of the Design Basis Earthquake (DBE) with $10 \%$ probability in 50 years (i.e. return period of 475 years) is $0.4 \mathrm{~g}$ and that of the Maximum Considered Earthquake (MCE) with 2\% probability in 50 years (i.e. return period of 2450 years) is $0.72 \mathrm{~g}$. Two structural design alternatives were considered. One alternative being a conventional ductile pier detailed according to the concrete design standard of New Zealand [28], and the other designed according to the principles of DAD. The latter implements techniques developed by Mander and Cheng [29] and the Precast Seismic Structural Systems (PRESSS) Program [30] to avoid damage by rocking with post-tensioning tendons to provide stiffness and dampers to provide supplemental energy dissipation. Both piers were designed for the same base shear capacity as found from a basic force-based seismic analysis. As shown in Figure 2, the DAD pier is smaller in size and has less longitudinal reinforcement than its ductile counterpart. On the other hand, the DAD pier also needs prestressing tendons and the external dampers which are not required in the ductile pier. The foundation design of both piers were the same, with the exception of the DAD pier requiring a steel plate at the pier-to-pile cap connection to allow rocking to occur without significant damage to the surrounding concrete. An approximate cost estimate indicates that the initial costs of these two piers are within 5\% of each other. A detailed explanation of the DAD pier along with results of bi-directional physical experimentation can be found elsewhere [31].

\section{Rapid IDA-EAL Method}

Comparative results for each step of the Rapid IDA-EAL procedure are presented in Figure ; and a summary of the calculations is shown in Table 3. A non-linear pushover curve was obtained for both systems as presented in Figure 3a. The damping-related factors $\xi_{\text {in }}$ and $\eta$ were taken as 
0.05 and 0.4 , respectively, for the ductile pier. This was calculated expecting the hysteresis behaviour of the pier to follow a modified Takeda hysteresis loop with unloading and reloading behaviour modelled by $\alpha=\beta=0.3$. For the DAD pier $\eta$ was taken as 0.125 . Since little data exists on this new system, $\eta$ was based on experimental results [31].

Maximum drift at the seismic centre of mass is considered to be an effective EDP for bridge piers because it is a good indicator of both global damage (toppling) and local damage (plastic hinging). Median IDA curves correlating the spectral acceleration (IM) and maximum drift (EDP) for the two piers are shown in Figure 3b. Limit states were assigned as prescribed in Table 1 using the previously discussed HAZUS guidelines. For the ductile pier, limits between DS1-2 and DS4-5 were established at the first yield of the longitudinal reinforcement and at the beginning of severe strength degradation resulting in toppling, respectively. Limit states DS2-3 and DS3-4 were found based on observed damage during physical testing [32]. The selection of these limits was based on the failure mechanisms described in Table 1. The two boundaries between the three damage states assigned to the DAD pier were established at the first yield of the post-tensioning tendons and at the onset of toppling failure, respectively. Based on the results of computational IDA analysis, the lognormal standard deviation at the design basis earthquake $\beta_{D B E}$ was taken as 0.2 and 0.15 for the ductile and DAD piers, respectively. In the case of the DAD pier, responses outside the $10^{\text {th }}$ and $90^{\text {th }}$ percentile values were neglected in calculating $\beta_{D B E}$ as the large variations in these extreme ranges significantly inflate the calculated value of $\beta$. The resulting hazard-survival curves are given in Figure 3c.

\section{Computational IDA-EAL}

To perform the computational IDA, a non-linear structural model was developed. The pier was idealized as a single-degree-of-freedom system; i.e. a lumped mass centreline column with rotational springs at its base. The hysteresis properties of the springs were calibrated based on experimental results presented by Solberg [31]. The ductile pier was modelled using the Takeda hysteresis loop combined with strength degradation after ductility of 8 . The DAD pier was 
modelled using two springs, one representing the bi-linear elastic behaviour inherent in posttensioned rocking systems and the other elasto-plastic spring representing energy dissipation. Ruaumoko2D [33], an inelastic dynamic time-history analysis program, was used to conduct the analysis. The Rayleigh elastic damping was taken as 5\% of the critical. Soil-structure interaction was not considered (i.e. firm soil site was assumed), nor were torsion and slab interaction effects.

As presented in Table 2, the same 20 records used by Vamvatsikos and Cornell [25] were adopted for this study. These records range in magnitude between 6.5 and 6.9 , have moderate epicentral distance, and recorded on firm soil. Current best practice suggests representing IM by the $5 \%$ damped spectral acceleration at the natural elastic period of the structure, $S_{a}\left(T_{1}, 5 \%\right)$. The natural period for both piers was approximately $T_{n}=1.0$ second, thus $S_{a}\left(T_{1}=1 \mathrm{sec}, 5 \%\right)$ was taken as IM. The twenty records were scaled between $0.1 \mathrm{~g}$ and $2.0 \mathrm{~g}$ with an increment of $0.1 \mathrm{~g}$, resulting in 400 separate analyses. The resulting plots are given in the first two rows of Figure 4 showing: (a) raw IDA data, and (b) sorted EDP data for each IM and accounting for variation.

\section{Financial Loss}

The assigned LR's are based on recommendations by HAZUS [15] presented in Table 1. These values were found from statistical analysis of actual repair cost data from the Loma Prieta and Northridge earthquakes. Since no damage is expected in the DAD pier, the LR's are either zero or one, except for the intermediate damage state DS2. Since DS2 implies minor yielding (not failure) of the post-tensioning tendons, the repair costs would be comparatively low to restore the structure to working order by tightening the tendons. Based on the cost of inspection coupled with the cost of checking and adjusting prestressing levels, $\mathrm{LR}_{2}$ is assigned a value of 0.01 .

With this data the seismic hazard-recurrence relationship is generated and hazard-survival curves are plotted in Figure $3 \mathrm{c}$ for the Rapid IDA-EAL method and in Figure $4 \mathrm{c}$ for the computational IDA-EAL method. The final EAL, calculated using the proposed Rapid IDA-EAL method was found to be $\$ 1,040$ and $\$ 190$ per $\$ 1$ Million of asset value for the ductile and DAD piers, respectively. Using the computational IDA-EAL method, the resulting EAL for the ductile 
and DAD pier was found to be $\$ 980$ and $\$ 140$ per $\$ 1 \mathrm{M}$ asset value, respectively. This is calculated from the area under the curves given in Figure $3 \mathrm{~d}$ and Figure $4 \mathrm{~d}$ for the rapid and computational IDA-EAL methods, respectively.

\section{Verification}

The computational IDA-EAL procedure presented above seems to provide good correlation with the Rapid IDA-EAL method. For both piers, EAL calculated from the two methods differed only by $\$ 50$ per $\$ 1 \mathrm{M}$ asset value. Figure 5a compares the median $\left(50^{\text {th }}\right.$ percentile $)$ IDA responses from the two methods for the two piers. Both curves agree quite well, especially at lower intensity levels. At higher intensity levels the variation in data increases somewhat; which can mainly be attributed to two reasons. First, as IM is scaled at the structure's fundamental elastic period, and the natural period elongates with the onset of inelastic behaviour, variations in response will increase due to an increased dispersion [7] Secondly, as the target displacement increases, the Rapid IDA-EAL method is more susceptible to error from hysteresis damping approximations. The fragility, hazardsurvival, and total loss curves obtained from the two methods are compared in Figure 5b, 5c, and 5d, respectively. Although slight differences between the two are evident, the data tends to match better at higher annual frequencies. Note that this portion of the curve (i.e. higher frequency range) largely governs the final EAL value, whereas low frequency events do not have a large influence on the final outcome.

\section{DISCUSSION}

\section{The Rapid IDA-EAL Method}

A primary aim of this study was to develop a practical method to rapidly estimate financial seismic risk. The proposed Rapid IDA-EAL method has shown to be a very powerful, yet simple, procedure for seismic risk assessment. By means of pushover analysis and a modified CSM, a median EDP-IM relationship can be established. Using a constant lognormal standard deviation, structural fragility can be found for defined damage states. All sources of variability and uncertainty can be combined and related to the annual frequency in the form of hazard-survival 
curves which can be integrated and multiplied with the corresponding loss ratios to arrive at EAL. The proposed method was verified using the computational IDA-EAL method with no assumed distribution. Results showed good correlation between the two approaches. Although further research may help to make the proposed procedures more robust, the methodologies, even in their present form, are a substantial improvement over current simplified methods. The Rapid IDA-EAL method will enable engineers to take into account the long-term financial implications in addition to the construction cost. Consequently, it will help the stake holders to make informed decisions when choosing the final design for new buildings and a seismic retrofit option for existing buildings. The Rapid IDA-EAL methodology has been verified using a rigorous methodology for a SDOF model for a bridge. The applicability of the Rapid IDA-EAL methodology for Multi-Degree of Freedom (MDOF) systems was not investigated, and further research is needed in this regard.

\section{Ductile Design versus DAD}

The resulting EAL for the ductile and DAD piers were of stark contrast, even though both piers had similar design basis. The ductile pier's vulnerability was dominated by minor damage occurring at relatively low drifts and moderate ground shaking levels. The DAD pier, on the other hand, was dominated by the ultimate failure condition, resulting in an annual risk of only $16 \%$ of that of the ductile system. Such an improvement of performance is attributed to the rocking concept, which is relatively new in earthquake engineering. Findings from this study suggest that current design practice, although adequate in protecting loss to life and limb, is deficient in protecting the structure from minor yet costly damage arising from frequent events. Improvement in this area, possibly through further development of DAD, is a necessary next step for PBEE. The findings of this and further studies related to DAD systems may be the evidence needed for DAD to become feasible in a highly competitive construction industry.

Not considered in this study is the significant additional risk associated with non-structural damage, downtime, and loss of life. Bridges are especially vital for the flow of goods and people; closure of key transportation arteries can have severe economic consequences. Bridges designed 
according to DAD will incur little to no residual displacement, allowing full operation even after large earthquakes. Non-structural damage will need to be considered in buildings, where it is likely to contribute significantly to global loss. Studies in these areas are in their infancy, and further work regarding such risk is necessary to fully address the viability of DAD.

\section{CONCLUSIONS}

Based on the findings of this research, the following conclusions can be drawn:

1. A Rapid IDA-EAL method has been established to assess seismic financial risk. A nonlinear static pushover curve was combined with the acceleration-displacement response spectrum using the capacity spectrum method to generate the median-spectrum compatible IDA curve to approximate the true median IDA curve. The median EDP value was related to damage states and loss ratios through damage and loss models, respectively. Thus generated loss hazard curve was integrated using a simplified equation that takes into account the median loss value and the combined dispersion factor to calculate EAL. Although loss ratios for different damage states are assumed to be crisp in the application shown, the proposed rapid IDA-EAL methodology can easily incorporate uncertainties in the assumed damage and loss models by combining them in the final dispersion factor used in the EAL equation.

2. An alternative method has been used for processing the results of IDA. This study has advanced the use of a distribution-free approach whereby IDA data is used without any preconceived probability distribution function. Other sources of uncertainty and randomness were combined into the analysis in an approximate sense.

3. Both the distribution-free rapid IDA-EAL method and the conventional computational IDA based method were compared through a practical application to reinforced concrete bridges. The Rapid IDA-EAL assessment approach showed good agreement with the full computational IDA-EAL approach. Results were well within the same magnitude and varied on average by $15 \%$. 
4. Through the use of the proposed financial risk methods, the seismic vulnerability of two bridge piers with very different detailing but comparable initial cost was examined. One pier, designed to avoid all forms of damage except from toppling, was shown to have an EAL approximately $80 \%$ less than a conventional ductile pier. 


\section{REFERENCES}

1. Deierlein GG, Krawinkler H, Cornell CA. A Framework for Performance-Based Earthquake Engineering. Pacific Conference on Earthquake Engineering. 2003. Christchurch, New Zealand.

2. Krawinkler H, Miranda E. Performance-Based Earthquake Engineering. Earthquake Engineering: From Engineering Seismology to Performance-Based Engineering 2004. Edited by Bozorgnia Y. and Bertero V.V. CRC Press: Boca Raton, FL.

3. Dhakal RP, Mander JB. Financial Risk Assessment Methodology for Natural Hazards. Bulletin of the New Zealand Society of Earthquake Engineering 2006; 39(2): 91-105.

4. Porter KA, Kiremidjian AS, LeGrue JS. Assembly-Based Vulnerability for Buildings and Its Use in Performance Evaluation, Earthquake Spectra 2001; 17(2): 291-312.

5. Aslani H, Miranda E. Probability-based Seismic Response Analysis. Engineering Structures 2005; 27(8): 1151-1163.

6. Mander JB, Dhakal RP, Mashiko N, Solberg KM. Incremental Dynamic Analysis Applied to Seismic Financial Risk Assessment of Bridges. Engineering Structures. (In Press).

7. Baker JW. Vector-valued Ground Motion Intensity Measures for Probabilistic Seismic Demand Analysis. Ph.D Dissertation 2005, Department of Civil and Environmental Engineering, Stanford University. 347 pages.

8. Cornell CA, Fatemeh JF, Hamburger RO, Foutch DA. 2002, Probabilistic Basis for 2000 SAC Federal Emergency Management Agency Steel Moment Frame Guidelines. Journal of Structural Engineering 2002; 128(4): 526-533.

9. Vamvatsikos D, Cornell CA. Incremental Dynamic Analysis. Earthquake Engineering and Structural Dynamics 2002; 31: 491-514.

10. Federal Emergency Management Agency (FEMA). Recommended Seismic Design Criteria for New Steel Moment-Frame Buildings. Report No. FEMA-350 2000; SAC Joint Venture, Washington, DC.

11. Porter KA, Beck JL. Simplified Estimation of Economic Seismic Risk for Buildings. Earthquake Spectra 2004; 20(4): 1239-1263.

12. Vamvatsikos D, Cornell CA. Direct Estimation of Seismic Demand and Capacity of MultiDegree-of-Freedom Systems through Incremental Dynamic Analysis of a Single Degree of Freedom Approximation. Journal of Structural Engineering 2005; 131(4): 589-599.

13. Jalayer F. Direct Probabilistic Seismic Analysis: Implementing Non-linear Dynamic Assessments. Ph.D Dissertation 2003, Department of Civil and Environmental Engineering, Stanford University. 272 pages.

14. Bradley BA, Dhakal RP, Cubrinovski M, Mander JB, MacRae GA. Improved Seismic Hazard Model with Application to Probabilistic Seismic Demand Analysis, Earthquake Engineering and Structural Dynamics 2007, DOI: 10.1002/eqe.727 (In Press).

15. Mander JB, Basoz N. Seismic fragility curve theory for highway bridges in transportation lifeline loss estimation. Optimizing Post-Earthquake Lifeline System Reliability, TCLEE Monograph No. 16. ASCE 1999; 31-40.

16. Shome N, Cornell CA, Bazzurro P, Carballo JE. Earthquakes, Records, and Nonlinear Responses. Earthquake Spectra 1998; 14(3): 469-500.

17. ATC-40. Seismic Evaluation and Retrofit of Concrete Buildings Volume 1. Applied Technology Council Report No. ATC-40 1996. 
18. Goel RK, Chopra AK. Improved Direct Displacement-Based Design Procedure for Performance-Based Seismic Assessment. Proceedings of 2001 Structures Congress 2001; Washington DC.

19. Miranda E, Ruiz-Garcia J. Evaluation of Approximate Methods to Estimate Maximum Inelastic Displacement Demands. Earthquake Engineering and Structural Dynamics 2002; 31: 539-560.

20. Iwan, WD. The Use of Equivalent Linearization in Performance Based Engineering. Proc. International Conference on Advances and New Challenges in Earthquake Engineering Research (ICAN-CEER) 2002; Harbin, China.

21. Lin YY, Chang KC. Evaluation of Damping Reduction Factors. Journal of Structural Engineering 2004; 133(9): 1667-1675.

22. Pekcan G, Mander JB, Chen SS. Fundamental Considerations for the Design of Non-Linear Viscous Dampers. Earthquake Engineering and Structural Dynamics 1999; 28: 1405-1425.

23. Lin YY, Miranda E, Chang KC. Evaluation of Dampening Reduction Factors for Estimating Elastic Response of Structures with High Dampening. Earthquake Engineering and Structural Dynamics 2005; 34: 1427-1443.

24. Kennedy RP, Cornell CA, Campbell RD, Kaplan S, Perla HF. Probabilistic Seismic Safety Study of an Existing Nuclear Power Plant. Nuclear Engineering and Design 1980; 59(2): 315338.

25. Vamvatsikos D, Cornell CA. Applied Incremental Dynamic Analysis. Earthquake Spectra 2002; 20(2): 523-553.

26. Ang AHS, Tang WH. Probability Concepts in Engineering Planning and Design: Volume I Basic Principles. John Wiley \& Sons 1975.

27. Aslani H., Miranda E., Delivering improved information on seismic performance thorough loss deaggregation, paper no 1126. $8^{\text {th }}$ National Conference on Earthquake Engineering. San Francisco, April 2006

28. NZS3101-95. Concrete Structures Standard: NZS3101. Standards New Zealand 1995; Wellington, New Zealand.

29. Mander JB, Chen CT. Seismic Resistance of Bridge Piers Based on Damage Avoidance Design. Technical Report NCEER-97-0014 1997. National Centre for Earthquake Engineering Research: Buffalo, NY.

30. Priestley MJN, Sritharan S, Conley JR, Pampanin S. Preliminary Results and Conclusions from the PRESSS Five-Story Precast Concrete Test Building, PCI Journal 1999; 44(6): 42-67.

31. Solberg KM. Financial and Experimental Explorations into the Viability of Damage Avoidance Design. Master of Engineering Thesis 2006. Dept. of Civil Engineering, University of Canterbury, Christchurch, New Zealand.

32. Dhakal RP, Mander JB, Mashiko N. Identification of critical ground motions for seismic performance assessment of structures. Earthquake Engineering and Structural Dynamics 2006; 35(8): 989-1008.

33. Carr AJ. RUAUMOKO: Inelastic Dynamic Computer Program. Computer Program Library, Department of Civil Engineering, University of Canterbury, Christchurch, New Zealand 2004. 
TABLES AND FIGURES

Table 1: Damage states index as defined by Hazus [15] and the loss ratios and range

\begin{tabular}{|c|c|c|c|c|c|c|}
\hline & Damage State & $\begin{array}{l}\text { Failure Mechanism } \\
\text { for RC bridge piers }\end{array}$ & Repair Required & Outage & $\begin{array}{l}\text { Ductile } \\
\text { LR }\end{array}$ & DAD LR \\
\hline DS1 & None & Pre-Yield & None & No & 0 & 0 \\
\hline DS2 & Minor / Slight & Post-Yield / Spalling & $\begin{array}{l}\text { Inspect, Adjust, } \\
\text { Patch }\end{array}$ & $<3$ days & $\begin{array}{c}0.03 \\
0.01-0.03\end{array}$ & $\begin{array}{c}0.01 \\
0-0.03\end{array}$ \\
\hline DS3 & Moderate & $\begin{array}{l}\text { Post-Spalling, Bar } \\
\text { Buckling }\end{array}$ & $\begin{array}{c}\text { Repair } \\
\text { Components }\end{array}$ & $<3$ weeks & $\begin{array}{c}0.08 \\
0.02-0.15\end{array}$ & - \\
\hline DS4 & $\begin{array}{l}\text { Major/ } \\
\text { Extensive }\end{array}$ & $\begin{array}{l}\text { Degrading of } \\
\text { Strength }\end{array}$ & $\begin{array}{c}\text { Rebuild } \\
\text { Components }\end{array}$ & $<3$ months & $\begin{array}{c}0.25 \\
0.10-0.40\end{array}$ & - \\
\hline DS5 & $\begin{array}{l}\text { Complete / } \\
\text { Collapse }\end{array}$ & Collapse & Rebuild Structure & $>3$ months & $\begin{array}{c}1 \\
0.30-1.00\end{array}$ & $\begin{array}{c}1 \\
0.30-1.00\end{array}$ \\
\hline
\end{tabular}

Table 2: Earthquake records adopted for IDA

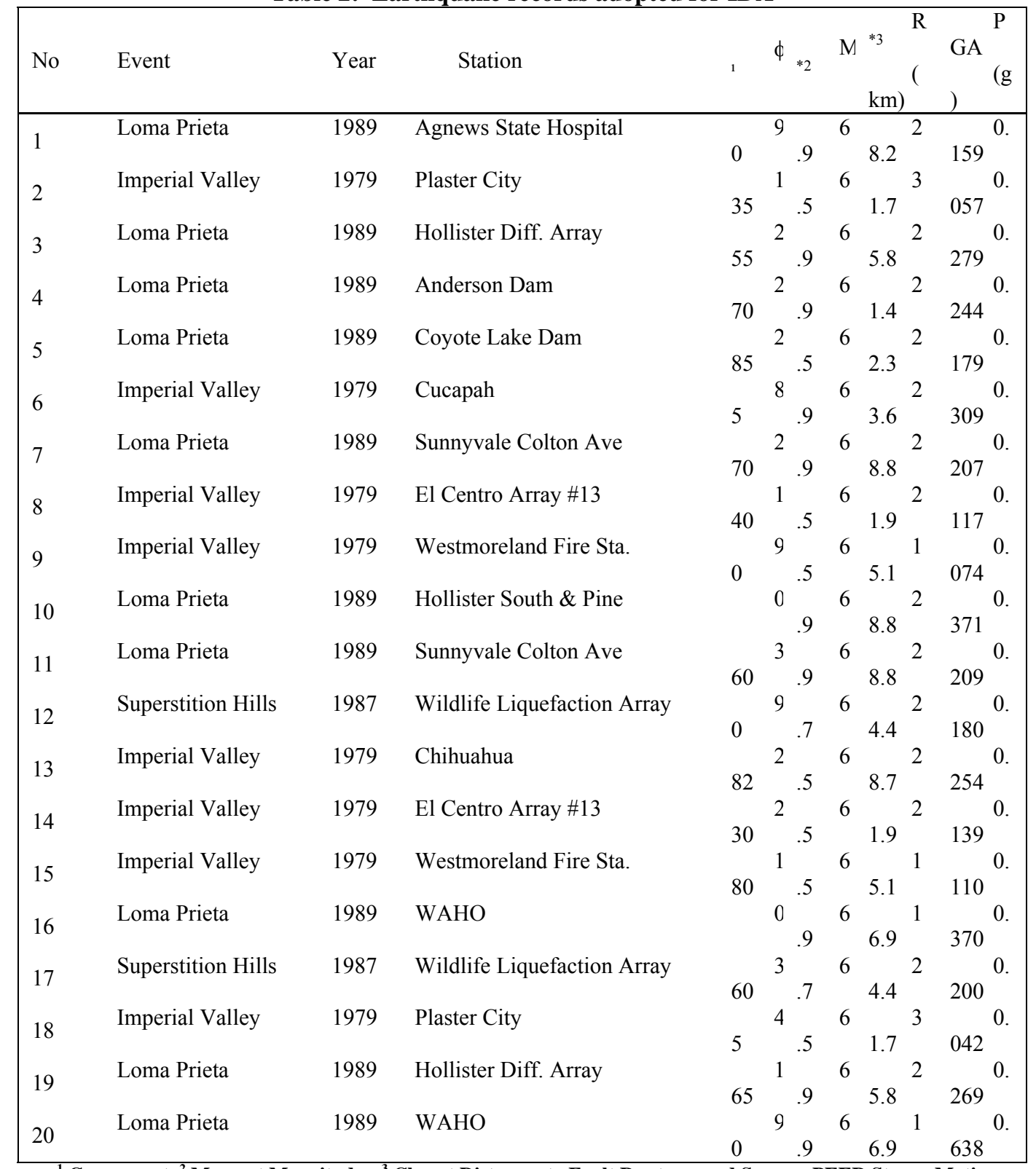

${ }^{1}$ Component, ${ }^{2}$ Moment Magnitudes, ${ }^{3}$ Closest Distances to Fault Rupture, and Source: PEER Strong Motion Database, http://peer.berkeley.edu/smcat/

Table 3: Summary of the Rapid IDA-EAL method

\begin{tabular}{|c|c|c|c|c|c|c|c|}
\hline $\begin{array}{l}\text { Damage } \\
\text { State }\end{array}$ & $\begin{array}{c}\theta \text { (EDP) } \\
\text { User } \\
\text { Defined }\end{array}$ & $\begin{array}{c}\text { IM } \\
f(\theta) \\
\text { Eq. }(13)-(15)\end{array}$ & $\begin{array}{c}f_{a} \\
f(I M) \\
\text { Eq. (19) }\end{array}$ & $\begin{array}{c}\text { LR } \\
\text { User } \\
\text { Defined }\end{array}$ & $\begin{array}{c}\Delta \mathrm{LR} \\
L R_{i}-L R_{i-1}\end{array}$ & $\begin{array}{c}\tilde{x} \\
f\left(L R, f_{a}\right) \\
\text { Eq. }(21)\end{array}$ & $\begin{array}{c}\text { EAL } \$ / \text { million } \\
f(\tilde{x}, \beta) \\
\text { Eq. } \\
(20) \text { or }(22)^{*}\end{array}$ \\
\hline
\end{tabular}




\begin{tabular}{|c|c|c|c|c|c|c|c|}
\hline \multicolumn{8}{|c|}{ Ductile Monolithic Pier } \\
\hline \multirow[t]{2}{*}{ DS1 } & & & & 0 & & & \\
\hline & $0.6 \%$ & 0.2048433 & 0.015707 & & 0.03 & 0.00046615 & $653^{*}$ \\
\hline \multirow[t]{2}{*}{ DS2 } & & & & 0.03 & & & \\
\hline & $2.2 \%$ & 0.627227 & 0.0005453 & & 0.05 & $2.4124 \mathrm{E}-05$ & 51 \\
\hline \multirow{2}{*}{ DS3 } & & & & 0.08 & & & \\
\hline & $3.6 \%$ & 0.8583003 & 0.0002126 & & 0.17 & $3.6531 \mathrm{E}-05$ & 85 \\
\hline \multirow{2}{*}{ DS4 } & & & & 0.25 & & & \\
\hline & $4.9 \%$ & 1.0387603 & 0.0001199 & & 0.75 & 0.00010133 & 252 \\
\hline DS5 & & & & & & Total $E A L=$ & $\$ 1040$ \\
\hline \multicolumn{8}{|c|}{ DAD Pier } \\
\hline \multirow[t]{2}{*}{ DS1 } & & & & 0 & & & \\
\hline & $3.0 \%$ & 0.570959 & 0.000723 & & 0.01 & $6.8719 \mathrm{E}-06$ & $10^{*}$ \\
\hline \multirow[t]{2}{*}{ DS2 } & & & & 0.01 & & & \\
\hline & $10.0 \%$ & 1.160943 & $8.58 \mathrm{E}-05$ & & 0.99 & $8.4630 \mathrm{E}-05$ & 180 \\
\hline DS5 & & & & 1 & & Total $E A L=$ & $\$ 190$ \\
\hline
\end{tabular}




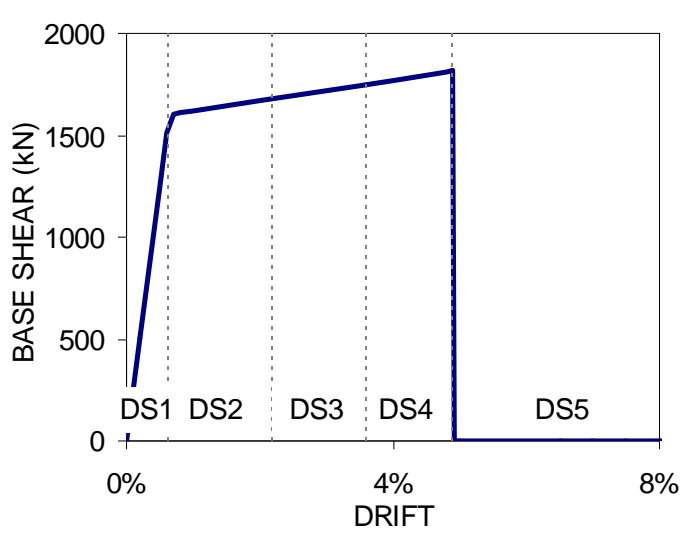

(a) Step 1:Conduct non-linear static pushover

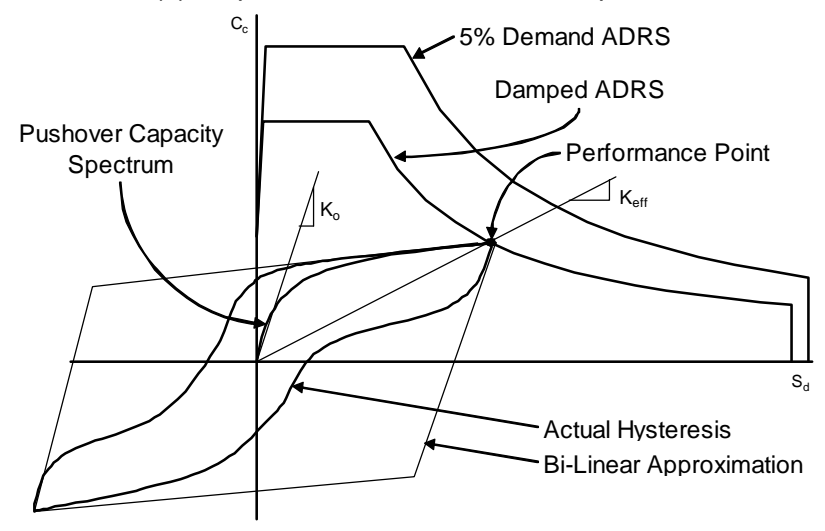

(c) Modified capacity spectrum method [18]

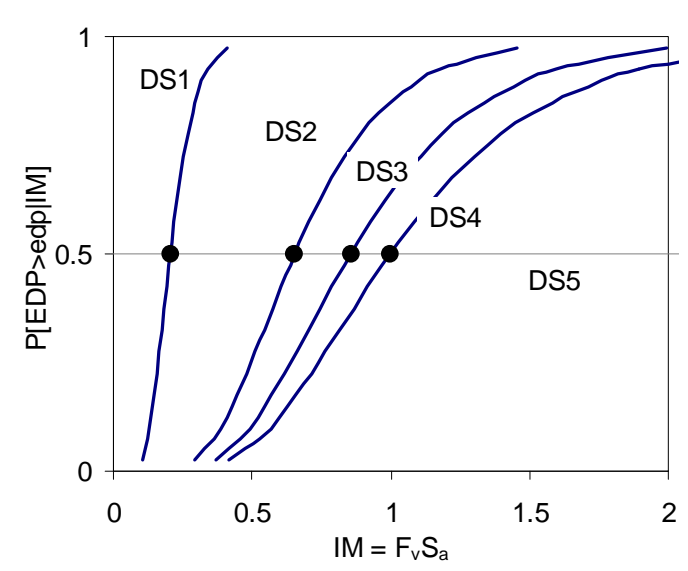

(e) Step 4: With assumed $\beta_{C / D}$ plot fragility curves

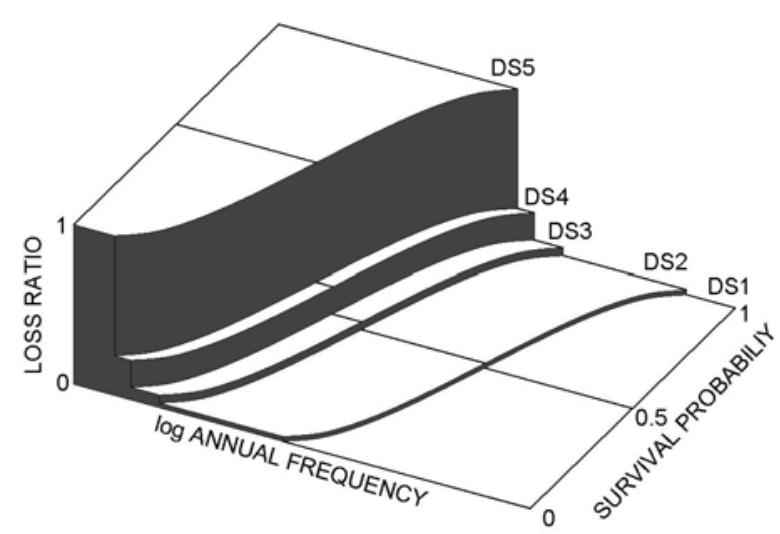

(g) Step 6a: Calculate hazard-survival curve.

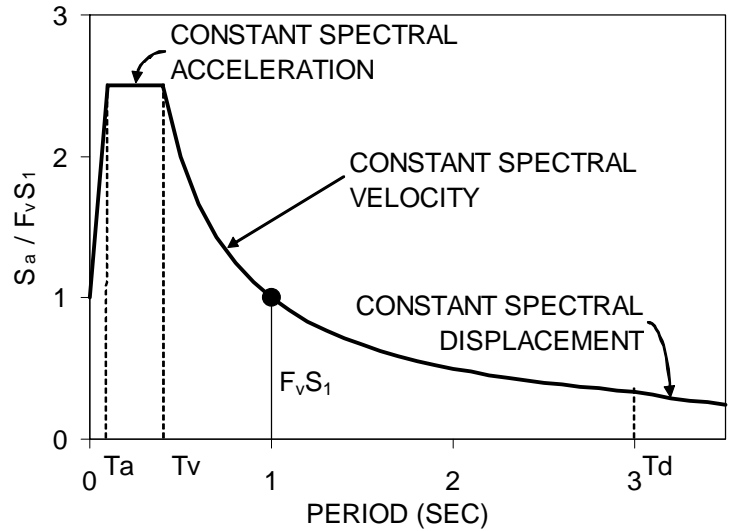

(b) Adopt standard spectral acceleration relationships

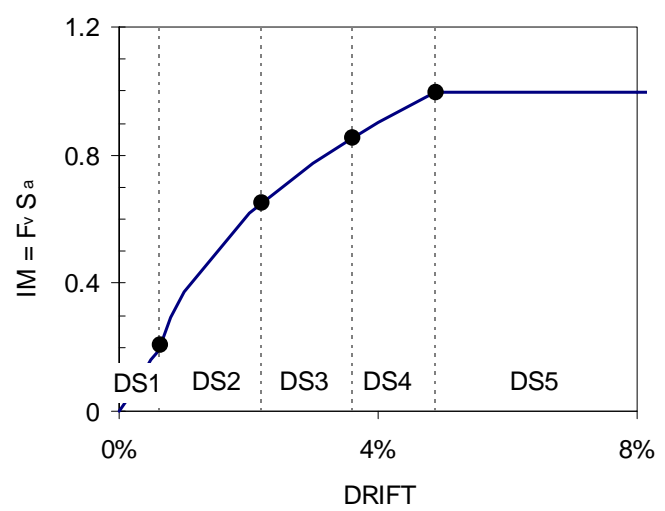

(d) Step 2: Form median spectrum compatible IDA curve Step 3: Define damage states and limits

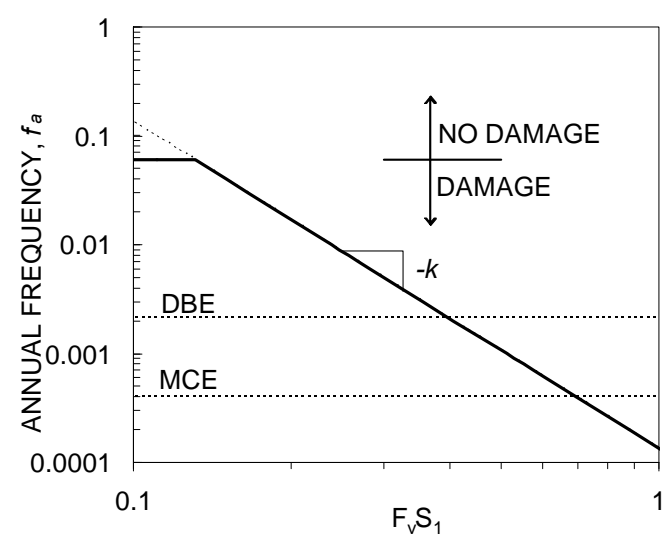

(f) Step 5: Define an earthquake recurrence relationship

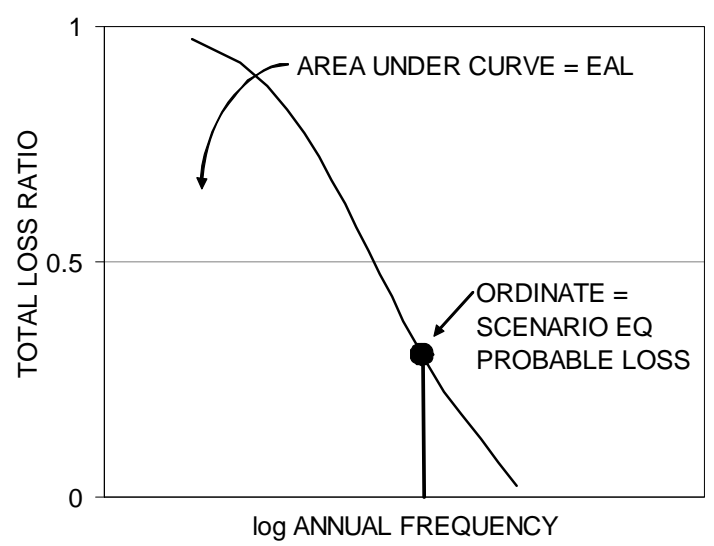

(h) Step 6b: Calculate EAL

Figure 1: Step for conducting a Rapid IDA-EAL risk assessment. 

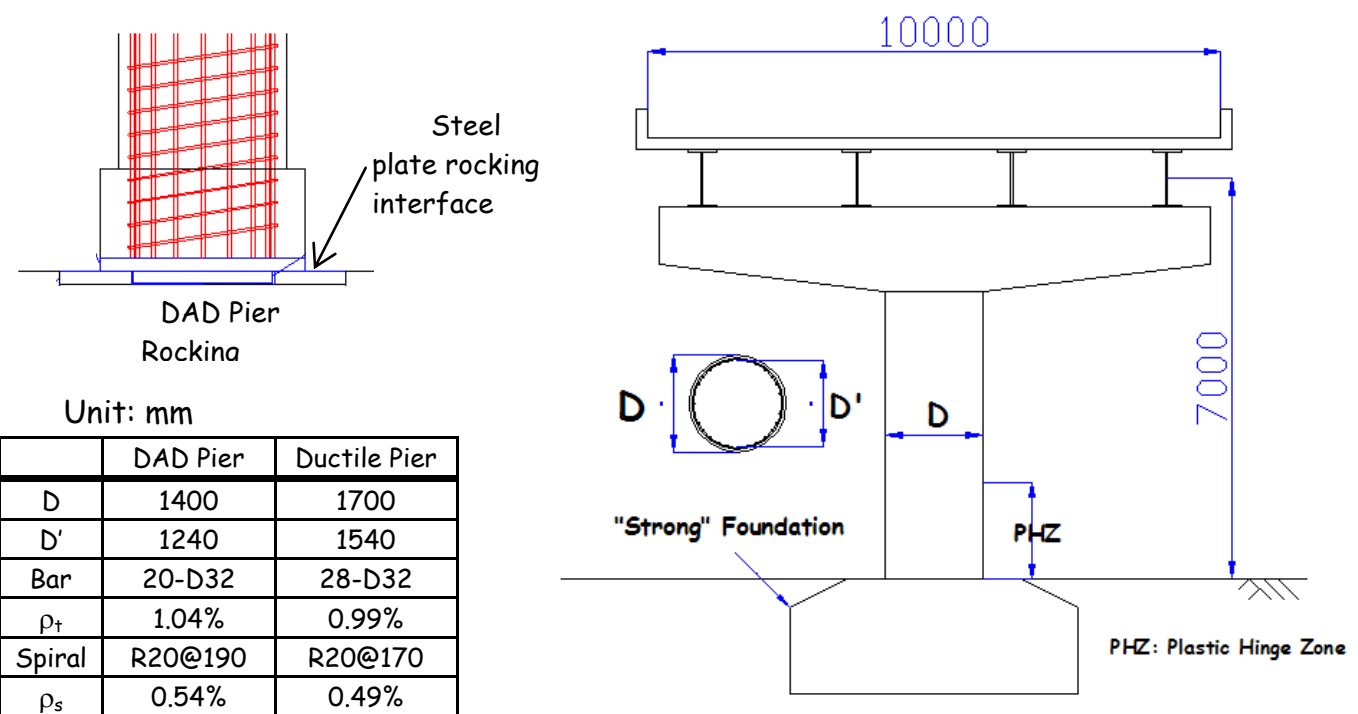

Unit: mm
\begin{tabular}{|c|c|c|}
\hline & DAD Pier & Ductile Pier \\
\hline$D$ & 1400 & 1700 \\
\hline$D^{\prime}$ & 1240 & 1540 \\
\hline Bar & $20-D 32$ & $28-D 32$ \\
\hline$\rho_{\dagger}$ & $1.04 \%$ & $0.99 \%$ \\
\hline Spiral & R20@190 & R20@170 \\
\hline$\rho_{s}$ & $0.54 \%$ & $0.49 \%$ \\
\hline
\end{tabular}

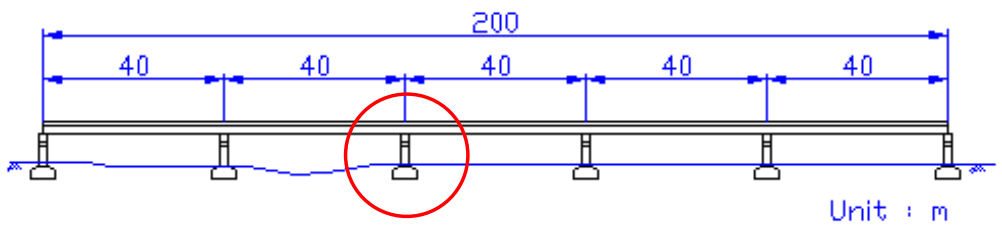

Figure 2: Prototype bridge and design details of the DAD and ductile piers. 


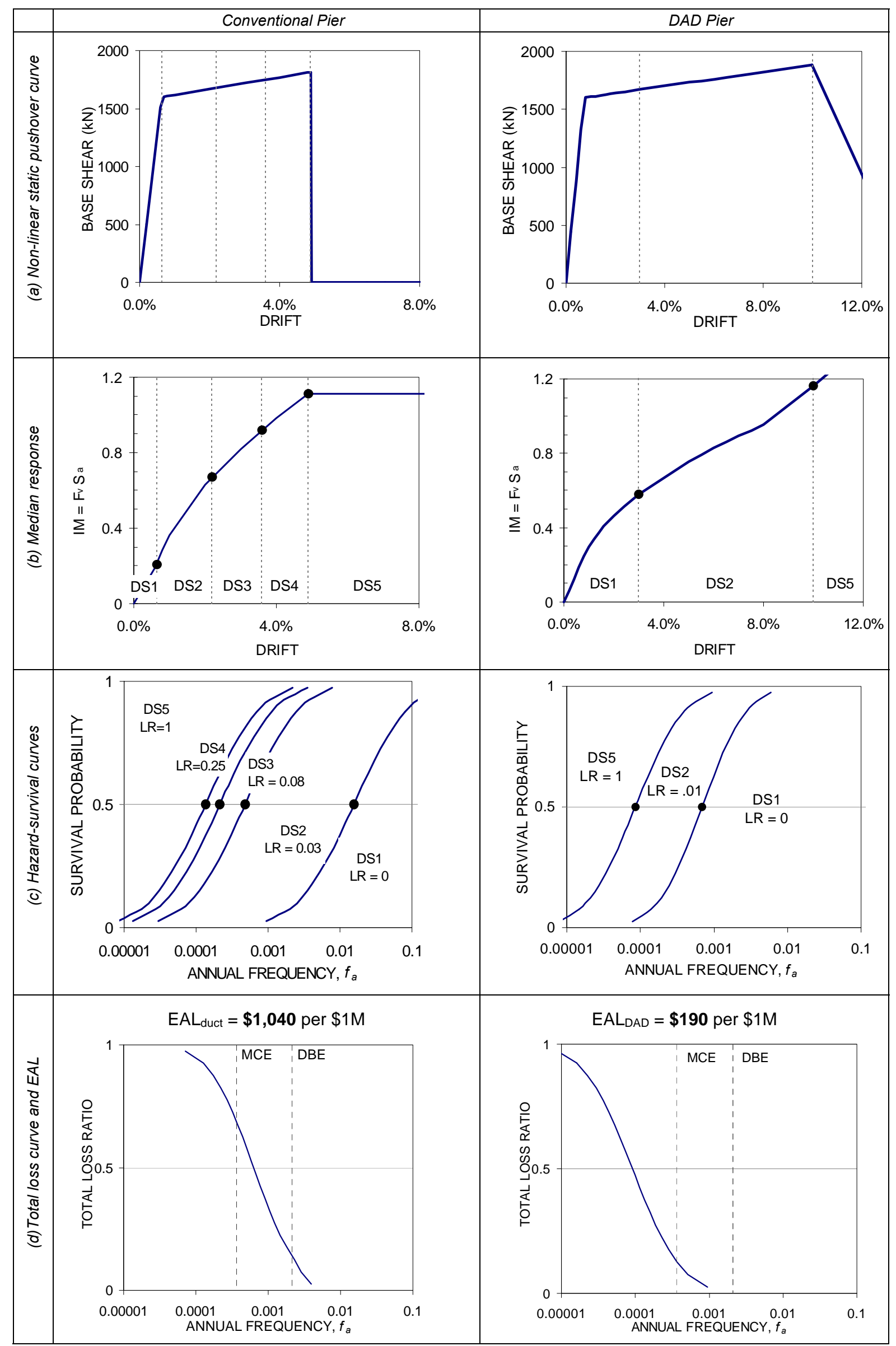

Figure 3: Rapid IDA-EAL case study of two RC bridge pier design alternatives. 


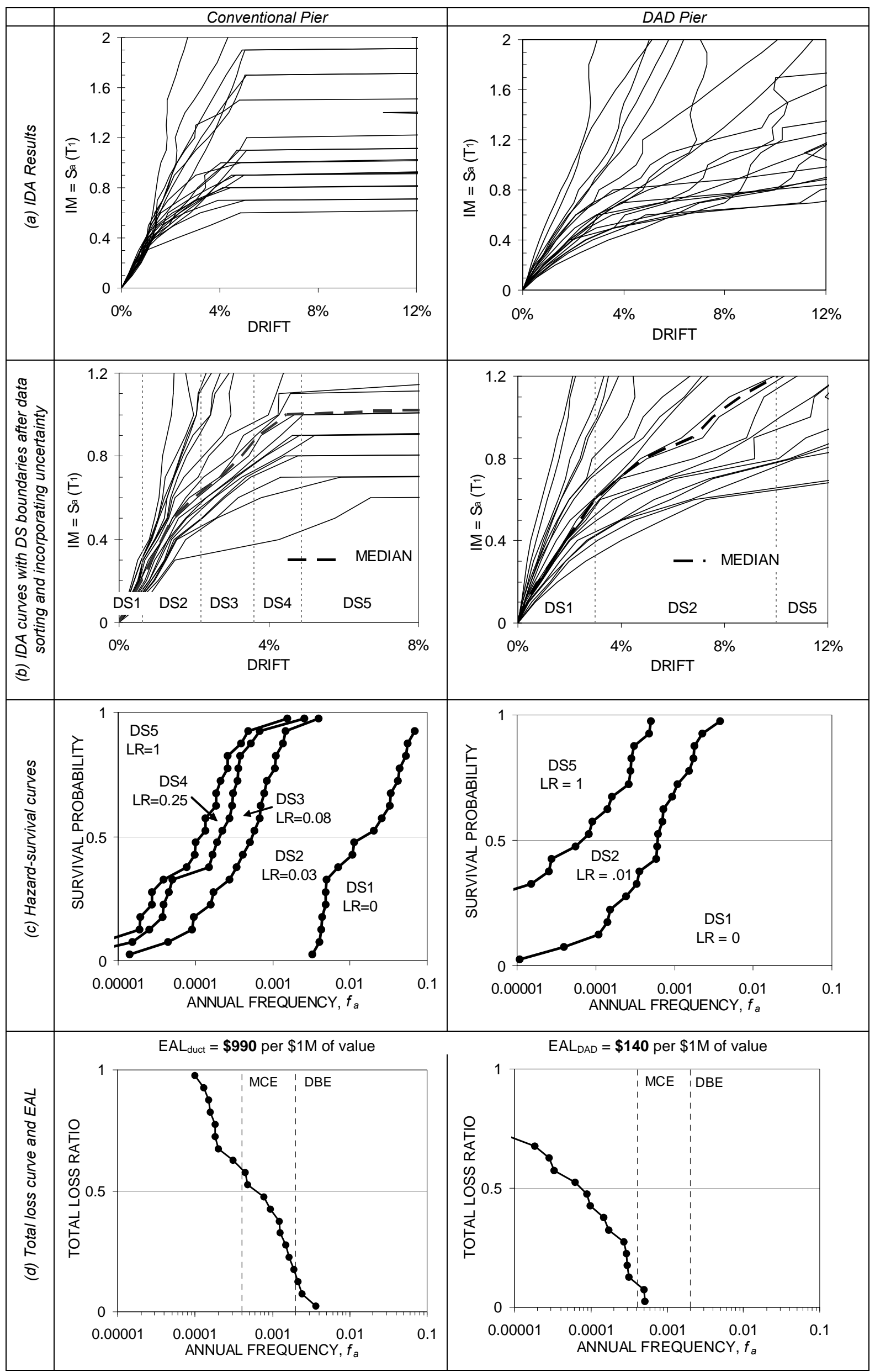

Figure 4: Results from computational IDA-EAL analysis 


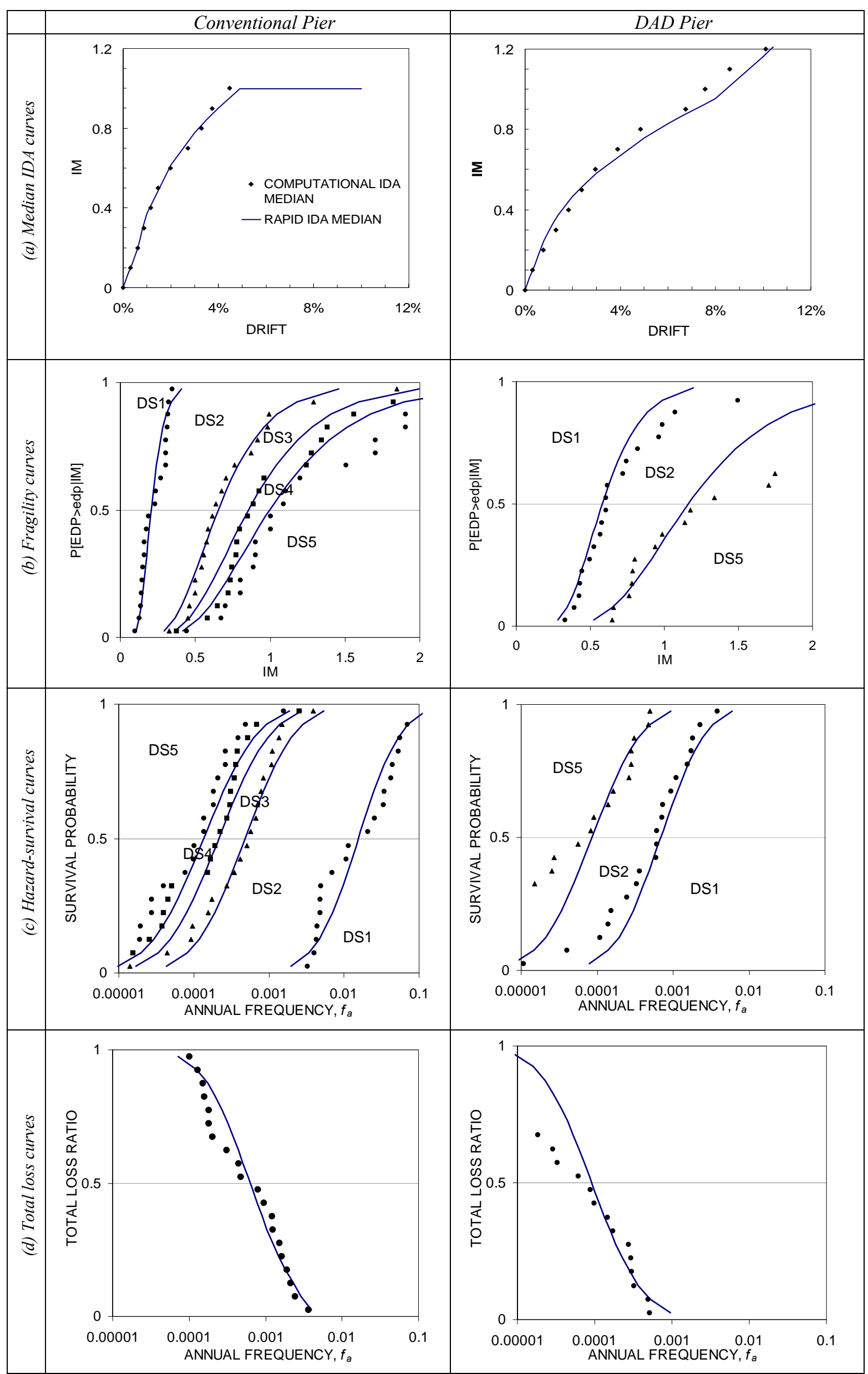

Figure 5: Comparison of Rapid IDA-EAL (solid lines) and the distribution-free method (symbols). 